\title{
Changes in Plasma Lipid Peroxidation and the Antioxidant System in Women with Breast Cancer
}

\author{
C. S. Sreenivasa Rao, D. Sarala Kumari \\ Department of Biochemistry, Sri Krishnadevaraya University, Anantapur-515003, \\ Andhra Pradesh, India \\ Email: bio.sreenivas@gmail.com
}

\begin{abstract}
Background: Oxidative stress plays a key role in carcinogenesis. Resistance of many cells against oxidative stress is associated with high intra cellular levels of glutathione (GSH). The antioxidant enzymes glutathione peroxidase (GPx) and catalase (CAT) are involved in the removal of lipid hydroperoxides.
\end{abstract}

Objectives: The aim of our study is to determine the role of oxidative stress in the induction of breast cancer and to establish the effect of antioxidants in the treatment of breast cancer.

Methods: The changes in lipid peroxidation and antioxidants were studied in breast cancer patients at different clinical stages. The results were compared with age and sex matched controls. Results: Plasma lipid peroxidation was found to be increased with the progression of breast cancer from stage I to stage IV. GSH levels in the erythrocytes of breast cancer patients were decreased in all clinical stages of breast cancer, when compared to control. CAT and GPx activities were elevated significantly from stage II to stage IV of breast cancer patients, whereas no significant change was observed in stage I, when compared to control. Serum iron levels were also increased significantly from stage II to stage IV. Conclusions: Enhanced lipid peroxidation may be a cause for the induction of breast cancer. The enhanced lipid peroxidation may be due to serum iron over load in these patients. Further, the serum iron levels were correlated with the extent of lipid peroxidation observed in different stages of breast cancer.

Keywords: Lipid peroxidation, Glutathione, Catalase, Glutathione peroxidase, Iron, Breast cancer. 


\section{Introduction}

Experimental evidence has shown that, oxidative stress is playing an important role in the process of carcinogenesis by means including mutagenesis [1]. Increased levels of oxygen free radicals (OFR) and loss of cellular redox homeostasis can be tumorigenic [2]. Cancer cells can produce large amounts of hydrogen peroxide and this may contribute to their ability to mutate and damage normal tissues and, moreover facilitates tumor growth and invasion [3]. OFR induced lipid peroxidation has been implicated in neoplastic transformation [4]. Oxidative stress especially lipid peroxidation, is known to be involved in carcinogenesis [5]. The polyunsaturated fatty acid chains of membrane lipids are susceptible to oxidizing radicals with the formation of lipid peroxide. Later, it is eventually decomposed to a variety of end products including malondialdehyde [6], which is not a normal constituent of erythrocytes and therefore its production provides a measure of the susceptibility of membrane lipid peroxidation.

Resistance of many cells against oxidative stress is associated with high intra cellular levels of glutathione [7]. GSH acts directly as a free radical scavenger by neutralizing $\mathrm{OH}^{\circ}$, restores damaged molecules by hydrogen donation, reduces peroxides, and maintains protein thiols in the reduced state [8]. The measurement of glutathione in tissues and biological fluids is used an index of the oxidative stress that occurs under different physiological and pathological conditions [9]. GSH and thiol redox status regulate expression of genes involved in the pathogenesis of different diseases, including cancer, AIDS, diabetes, or atherosclerosis [10].

In the erythrocytes $\mathrm{H}_{2} \mathrm{O}_{2}$ of the enzymatic detoxification pathways, selenium dependent glutathione peroxidase play an essential part in the metabolism of $\mathrm{H}_{2} \mathrm{O}_{2}$, fatty acid hydro peroxides, and phospholipid hydroperoxides in mammalian cells [11]. GPx initiates a repair mechanism whenever an oxidative challenge could result in peroxidation of complex biochemical compounds such as lipids and nucleic acids [12]. So, it plays an important role in number of cellular defense mechanisms essential for the survival of the cell.

The antioxidant enzyme, catalase, is widely distributed in all animal tissues and high activity is found in red blood cells. Studies have shown that the administration of catalase results in protection against $\mathrm{H}_{2} \mathrm{O}_{2}$ mediated lipid peroxidation [13]. Catalase decomposes $\mathrm{H}_{2} \mathrm{O}_{2}$ without generation of free radicals by minimizing one electron transfers. Hence, a protective role against free radicals may be the main physiological function of catalase [14].

Iron is an essential component of hemoglobin and myoglobin. It is also an important part of some enzymes, in the form of heme (e.g. Xanthine oxidase). Knutson et al [15], reported significant increase in lipid peroxidation in high iron loaded experimental animals suggesting iron excess promote oxidative stress and may involve mitochondrial dysfunction as observed in aging and associated 
degenerative diseases. Iron has been recognized to potentiate carcinogenesis in several different organ systems and is an important risk factor for breast cancer [16].

\section{Patients and Methods}

Forty newly diagnosed breast cancer patients (ten at each stage), ranging in age from 32 to 65 years from Department of Oncology, Govt. General Hospital, Kurnool, Apollo Medial Centre, Kurnool (A branch of Apollo Hospitals, Hyderabad) and Gowri Gopal Hospitals, Kurnool, who had not undergone any previous treatment were chosen for this study. An equal number of age matched normal women served as control. Blood was obtained by venous puncture in a sterile tube and was allowed to clot. Serum was separated by centrifugation at $1000 \mathrm{~g}$ for 15 minutes. For plasma, blood was collected by venous arm puncture in a heparinized tube and plasma was separated by centrifugation at $1000 \mathrm{~g}$ for 15 minutes. Blood samples obtained from breast cancer patients were analyzed together with an equal number of age and sex matched normal healthy subjects.

Lipid peroxidation was estimated as evidence by the formation of thiobarbituric acid reactive substances like malondialdehyde (MDA) according to the method of Yagi [17]. Total reduced glutathione content was measured by the method of Ellman [18]. This method is based on the development of a yellow color when 5, 5-dithio bis-2-nitro benzoate (DTNB) is added to compounds containing sulfhydryl groups. The activity of glutathione peroxidase was determined according to the method of Rotruck et al [19]. Catalase was assayed by the method of Sinha [20]. Iron was estimated by Wong's method [21]. The data for biochemical analysis were expressed as mean \pm S.D. t-test was applied to determine the significance of various biochemical changes among the clinical stages (I, II, III and IV) and controls.

\section{Results}

Table 1 shows the extent of lipid peroxidation in plasma of normal subjects and patients with breast cancer at four different stages. Lipid peroxidation was found to be significantly raised in breast cancer patients, when compared to control. The extent of lipid peroxidation was found to be increased with the progression of breast cancer from stage-I to stage-IV. Lipid peroxidation was enhanced by $25 \%$ and $50 \%$ in stage-I and stage-II breast cancer patients respectively when compared to the control. Markedly increased lipid peroxidation was observed in advanced stages of breast cancer (Stage-III \& IV). 
Table 1:Changes in the levels of plasma lipid peroxidation in breast cancer patients at various stages and normal control (Mean + SD).

\begin{tabular}{|c|c|c|c|c|c|c|}
\hline \multirow[b]{2}{*}{ Parameter } & \multirow[b]{2}{*}{$\begin{array}{c}\text { Control } \\
\mathbf{n}=\mathbf{1 0}\end{array}$} & \multirow{2}{*}{$\begin{array}{c}\text { Total } \\
\text { Breast } \\
\text { Cancer } \\
\text { Patients } \\
n=40\end{array}$} & \multicolumn{4}{|c|}{ Breast cancer patients } \\
\hline & & & $\begin{array}{c}\text { Stage-I } \\
\mathbf{n}=10\end{array}$ & $\begin{array}{c}\text { Stage-II } \\
\mathbf{n}=\mathbf{1 0}\end{array}$ & $\begin{array}{c}\text { Stage- } \\
\text { III } \\
\mathbf{n}=10\end{array}$ & $\begin{array}{c}\text { Stage- } \\
\text { IV } \\
\mathbf{n}=\mathbf{1 0}\end{array}$ \\
\hline $\begin{array}{c}\text { Lipid } \\
\text { Peroxidation } \\
\text { (mmdes of } \\
\text { MDA/ml } \\
\text { plasma) }\end{array}$ & $\underset{0.01}{0.04} \pm$ & $\begin{array}{r}0.087^{\mathrm{a}} \\
\pm 0.032\end{array}$ & $\begin{array}{l}0.05^{\mathrm{a}} \\
\pm 0.04\end{array}$ & $\begin{array}{l}0.07^{\mathrm{a}} \\
\pm 0.01\end{array}$ & $\begin{array}{c}0.116^{\mathrm{a}} \pm \\
0.01\end{array}$ & 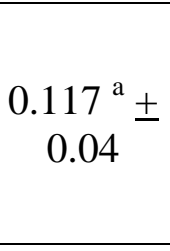 \\
\hline $\begin{array}{c}\text { GSH }(\mu \mathrm{g} / \mathrm{dl} \\
\text { Plasma })\end{array}$ & $\begin{array}{l}53.05 \\
\pm 3.0\end{array}$ & $\begin{array}{l}29.77^{\mathrm{a}} \\
\pm 3.43\end{array}$ & $\begin{array}{c}48.05^{\mathrm{a}} \\
\pm 2.1\end{array}$ & $\begin{array}{l}33.05^{\mathrm{a}} \\
\pm 4.27\end{array}$ & $\begin{array}{l}20.61^{\mathrm{a}} \\
\pm 3.69\end{array}$ & $\begin{array}{r}17.37^{\mathrm{a}} \\
\pm 03.69\end{array}$ \\
\hline $\begin{array}{l}\text { Iron } \\
(\mu \mathrm{g} / \mathrm{dl})\end{array}$ & $\begin{array}{r}156.9 \\
+17.3 \\
\end{array}$ & $\begin{array}{l}277.8^{\mathrm{a}} \\
\pm 20.3\end{array}$ & $\begin{array}{c}163.7 \\
10.4\end{array} \pm$ & $\begin{array}{l}199.5^{\mathrm{a}} \\
\pm 19.1\end{array}$ & $\begin{array}{l}311.17^{\mathrm{a}} \\
\pm 22.7\end{array}$ & $\begin{array}{c}443.18^{\mathrm{a}} \\
+29.1 \\
\end{array}$ \\
\hline
\end{tabular}

a - Significantly different from controls $(\mathrm{P}<.05)$

Table 2 shows the changes in reduced glutathione levels in the erythrocytes of breast cancer patients at various stages and normal control. GSH levels were found to be significantly reduced in all clinical stages of breast cancer patients, when compared to control. GSH levels were found to be decreased by $9.4 \%$ to $68 \%$ from stage- I to Stage-IV of cancer patients compared to control, indicating the percentage of decrease in GSH advances from stage-I to Stage-IV $(9.4 \%, 37 \%$, $61 \%, 68 \%)$.

Table 2: Changes in the activity of glutathione peroxidase and catalase in the blood of cancer patients at various stages and normal control (mean \pm SD)

\begin{tabular}{|c|c|c|c|c|c|c|}
\hline \multirow[b]{2}{*}{ Parameter } & \multirow[b]{2}{*}{$\begin{array}{c}\text { Control } \\
\mathbf{n}=10\end{array}$} & \multirow{2}{*}{$\begin{array}{c}\text { Total } \\
\text { Breast } \\
\text { Cancer } \\
\text { Patients } \\
\text { n=40 } \\
\end{array}$} & \multicolumn{4}{|c|}{ Breast cancer patients } \\
\hline & & & $\begin{array}{c}\text { Stage-I } \\
\mathbf{n}=10\end{array}$ & $\begin{array}{c}\text { Stage-II } \\
\mathbf{n}=10\end{array}$ & $\begin{array}{c}\text { Stage-III } \\
\mathbf{n}=10\end{array}$ & $\begin{array}{c}\text { Stage-IV } \\
n=10\end{array}$ \\
\hline $\operatorname{GPx}\left(\mathrm{U}^{\mathrm{A}}\right)$ & $\begin{array}{c}177.3 \pm \\
31.0\end{array}$ & $\begin{array}{c}203.36^{\mathrm{a}} \pm \\
25.57^{-}\end{array}$ & $\begin{array}{c}170.06 \pm \\
15.0\end{array}$ & $\begin{array}{c}205.01^{\mathrm{a}} \\
\pm 18.8 \\
\end{array}$ & $\begin{array}{r}216.5^{\mathrm{a}} \\
+22.8 \\
\end{array}$ & $\begin{array}{r}221.9^{\mathrm{a}} \\
+\quad 45.7 \\
\end{array}$ \\
\hline $\begin{array}{c}\text { Catalase } \\
\left(\mathrm{U}^{\mathrm{B}}\right)\end{array}$ & $\begin{array}{c}0.05 \pm \\
0.001\end{array}$ & $\begin{array}{l}0.063^{\mathrm{a}} \\
\pm 0.007\end{array}$ & $\begin{array}{c}0.05 \pm \\
0.007\end{array}$ & $\begin{array}{r}0.063^{\mathrm{a}} \\
\pm 0.007\end{array}$ & $\begin{array}{r}0.069^{\mathrm{a}} \\
\pm 0.007\end{array}$ & $\begin{array}{l}0.069^{\mathrm{a}} \\
\pm 0.007\end{array}$ \\
\hline
\end{tabular}

$\mathrm{U}^{\mathrm{A}}-\mu \mathrm{g}$ of GSH consumed/min/gram $\mathrm{Hb}$

$\mathrm{U}^{\mathrm{B}}-\mu \mathrm{g}$ of $\mathrm{H}_{2} \mathrm{O}_{2}$ decomposed/min/g Hb

a- significantly different from control $(\mathrm{P}<.05)$ 
Table 2 shows the alterations in the activity of glutathione peroxidase in breast cancer patients compared to normal subjects. The activity of GPx was found to be increased significantly in breast cancer patients. GPx activity was elevated significantly from stage - II to Stage -IV breast cancer patients (4\% to 25\%), whereas no significant change was observed in stage I breast cancer patients, when compared to controls

In present study, catalase activity was estimated in all clinical stages of breast cancer and normal controls. Catalase activity was found to be increased significantly from stage - II to stage - IV of breast cancer patients when compared to the normal controls. CAT activity was increased by $26 \%$ in stage II and $38 \%$ in stage III \& IV, compared to controls. No significant change was observed in stage I breast cancer patients

In present study, serum iron levels were estimated among breast cancer patients in relation to different clinical stages and in normal subjects. Serum iron levels were found to be increased in breast cancer patients, when compared to control. Serum iron levels were not significantly altered in stage-I breast cancer patients, whereas markedly elevated serum iron levels were observed in advanced stages of breast cancer.

\section{Discussion}

Plasma MDA levels have been studied as an indicator of lipid peroxidation in human. Different results with regard to the levels of lipid peroxidation products, especially MDA in various tumors including breast cancer have been reported. Gerber et al [22], have reported that patients with breast cancer have significantly lower plasma MDA levels when compared to healthy controls. However, Faber et al [23], have shown that the patients with breast cancer have higher MDA levels when compared to controls. Those reporting higher levels of oxidative stress, including increased MDA levels, in patients with various cancers have interpreted their data as the oxidative stress playing an important role in the process of carcinogenesis by means of including mutagenesis [24]. However, some researchers have reported decreased levels of lipid peroxidation products and oxidative stress along with increased antioxidant status in cancer patients [25]. So, in the present study, lipid peroxidation was assessed in cancer patients and compared with control. Increased levels of lipid peroxidation products play a role in the early phases of tumor growth [26]. Marnet LJ [27], reported that, the endogenous MDA has also been reported to cause mutagenesis in various tissues by forming DNA adducts. The potential of MDA formation in formation of cathcolestrogen metabolites have been proposed for its role in estrogen induced carcinogenesis [28].

Damage to the breast epithelium by oxygen free radicals can lead to fibroblast proliferation, epithelial hyperplasia, cellular atypia and breast cancer. Studies have shown increased lipid peroxidation in solid tumors [29]. 
In conclusion, MDA level seems an important biomarker for chemoprevention and can be used as a surrogate marker for chemoprevention studies. Additionally restoration of the endogenous levels of important potential carcinogenic factors, such as MDA might have a role in chemoprevention studies for cancer and warrants further research.

GSH acts directly as a free radical scavenger by neutralizing $\mathrm{OH}^{\circ}$, restores damaged molecules by hydrogen donation, reduces peroxides, and maintains protein thiols in the reduced state [8]. GSH and thiol redox status regulate expression of genes involved in the pathogenesis of different diseases, including cancer, AIDS, diabetes, or atherosclerosis [10].

Thus the deceased GSH levels in different stages of breast cancer coincide with the enhanced lipid peroxidation observed in corresponding stages of breast cancer patients. Decreased GSH levels in breast cancer patients may be attributed to increased utilization to scavenge lipid peroxides as well as sequestration by tumor cells. Navarro et al [30], reported that, the GSH levels are reduced may be due to a decrease in available substrate for GSH synthesis.

The elevation of erythrocyte GPx activity in breast cancer patients and progression of its elevation from stage II to stage IV may be a marker of cell proliferation by eliminating $\mathrm{H}_{2} \mathrm{O}_{2}$ and other hydroperoxides. Similar to our study, Doroshow [31], and Kumaraguruparan et al [32], were also reported enhanced GPx in breast tumors. The enhanced activity of GPx in the present study also correlated with decreased GSH levels of plasma. Inspite of enhanced GPx activity the plasma lipid peroxidation was found to be enhanced in breast cancer patients indicating that the protection provided by GPx is not sufficient to counterbalance the oxidative stress observed in these patients. Contrary to our reports, Robinson et al [33], reported decreased GPx activity with progression of neoplastic transformation and in erythrocytes of gastric cancer patients respectively. Hong et al [34], reported that GPx is a key enzyme in the defense against oxidative damage and cell survival was correlated directly with the GPx activity.

The increase in catalase activity could be a protective mechanism for the cells due to the tumor induced hyper production of reactive oxygen species (ROS). Over expression of antioxidants have been documented in wide varieties of malignant tumors including breast cancer [35]. Halliwell [36], reported that oxidative stress can cause up regulation of antioxidant enzymes that render cells more resistant to subsequent oxidative insult.

Further, Lu et al [37], reported that cancer cells with increased activity of antioxidant enzymes are presumed to escape recognition by cytotoxic lymphocytes. Unlike to our reports, decreased erythrocyte catalase activity was reported in patients with stomach cancer and in cancerous tissue in human hepatoma and liver tumor bearing mice [38], others have reported reduced antioxidant activities in lung tumors [39]. The increase in lipid peroxidation observed in breast cancer patients in the present study was not counterbalanced by the enhanced antioxidant defense enzymes such as GPx and catalase. Moreover, 
these enzymic changes may suggest possible cancer induced alterations in the regulation of gene expression in the pluripotent stem cells, or may reflect a more rapid turnover of the red blood cells.

Studies of severe iron overload modeling hemochromatosis have reported increased hepatic lipid peroxidation, nuclear DNA damage, and mitochondrial dysfunction [40]. The severe iron overload of mitochondria has been fund to induce mitochondrial DNA damage [41]. Iron can catalyze conversion of $\mathrm{H}_{2} \mathrm{O}_{2}$ into $\mathrm{OH}^{\circ}$, the primary ROS responsible for DNA damage. Thus the enhanced serum iron levels in the present study may enhance the oxidative stress in the breast cancer patients. Iron has been recognized to potentiate carcinogenesis in several different organ systems and is an important risk factor for breast cancer [42]. For reasons not fully understood, iron accumulates in intracellular complexes with ferritin storage protein as a function of age. Thus, males and females reveal progressive iron accumulation with age, which is especially enhanced in post-menopausal women [43], whose incidence of breast cancer is increased.

Importantly, serum and breast ferritin levels are substantially elevated in breast carcinoma [44], and have been directly linked to mammary carcinogenesis through ROS [45]. The enhanced lipid peroxidation may be due to increased serum iron levels in these patients. Further, the serum iron levels were correlated with the extent of lipid peroxidation observed in different stages of breast cancer. It has been suggested that elevated ferritin/Iron complexes may supply the unusual needs for iron during proliferation of mammary tissue in normal or breast carcinoma cells. However, the need for iron in mammary gland cell growth may also substantially contribute to an unusual risk for ROS mediated injury. Treatment with ROS scavenging antioxidants, inhibition of critical ROS generating enzymes like xanthine oxidoreductase, reduction of iron intake, and reduced alcohol consumption by women in higher age dependent risk categories could significantly modulate the incidence of breast cancer.

\section{References}

[1] G.Ray, S. Batra, N.K.Shukla, S.Deo, V. Raina, S.Ashok, S.A, Lipid peroxidation free radical production and oxidant status in breast cancer, Breast Cancer Res Treat 59 (2000) 163-170.

[2] P.A.Cerutti, Oxy- radicals and cancer, Lancet 344 (1994) 862-863.

[3] T.P.Szatrowski, C.F.Nathan, Production of large amounts of hydrogen peroxide by human tumor cells, Cancer Res 51 (1991) 794-798.

[4] D.Hristozov, V.Gadjeva, T.Vlaykova, G.Dimitrov, Evaluation of oxidative stress in patients with cancer, Arch Physiol Biochem 109 (2001) 331-336.

[5] M.A.Trush, T.W.Kensler, An overview of the relationship between oxidative stress and chemical carcinogenesis, Free Radic Biol Med 10 (1991) 201-209. 
[6] R.J.Trotta, S.G.Sullivan, A.Stern, Lipid peroxidation and haemoglobin degradation in red blood cells exposed to t-butyl hydroperoxide. Effects of the hexose monophosphate shunt as mediated by glutathione and ascorbate, Biochem j 204 (1982) 405-415.

[7] A.Meister, Glutathione deficiency produced by inhibition of its synthesis, and its reversal: Application in research and therapy, Pharmacol Ther 51 (1991) 155-194.

[8] R.S.Pavri, A.D.Gupta, A.J.Baxi, S.H.Advani, Further evidence for oxidative damage to hemoglobin and red cell membrane in leukemia, Leuk Res 7 (1983) 729-733.

[9] B.J.Mills, J.P.Richie Jr, C.A.Lang, Glutathione disulfide variability in normal human blood, Anal Biochem 222 (1994) 95-101.

[10] C.K.Sen, L.Packer, Antioxidant and redox regulation of gene transcription, FASEB J 10 (1996) 709-720.

[11] Chu FF, Doroshow JH, Esworthy RS.Expression, characterization, and tissue distribution of a new cellular selenium-dependent glutathione peroxidase, GSHPX-GI. J Biol Chem 268 (1993) 2571-6.

[12] Uday Bandyopadhyay, Dipak Das, Ranajit K. Banerjee.Reactive oxygen species: oxidative damage and pathogenesis. Current Science 77 ( 1999) 658 -66 .

[13] Corrocher R, Casaril M, Bellisola G, Gabrielli GB, Nicoli N, Guidi GC, De Sandre G.Severe impairment of antioxidant system in human hepatoma.Cancer 58 ( 1986) 1658-62.

[14] Mueller S, Riedel HD, Stremmel W.Direct evidence for catalase as the predominant $\mathrm{H} 2 \mathrm{O} 2$-removing enzyme in human erythrocytes.Blood 90 ( 1997) 4973-8.

[15] Knutson MD, Walter PB, Ames BN, Viteri FE.Both iron deficiency and daily iron supplements increase lipid peroxidation in rats.J Nutr 130 (2000) 621-8.

[16] Elliott RL, Elliott MC, Wang F, Head JF.Breast carcinoma and the role of iron metabolism. A cytochemical, tissue culture, and ultrastructural study.Ann N Y Acad Sci 698 (1993) 159-66.

[17] Yagi K.Lipid peroxides and human diseases. Chem Phys Lipids 45 (1987) 337-51.

[18] Ellman GL. Tissue sulfhydryl groups. Arch Biochem Biophys 82 (1959) 707.

[19] Rotruck JT, Pope AL, Ganther HE, Swanson AB, Hafeman DG, Hoekstra WG.selinium: Biochemical roles as a component of gluathione peroxidase. Science 1973; 179: 588-90.

[20] Sinha AK.Calorimetric assay of catalase. Anal Biochem 47 (1972) 389-94.

[21] San Yin Wong. Colorimetric determination of iron and hemoglobin in blood.II. J Biol Chem 55 (1923) 421. 
[22] Gerber M, Astre C, Ségala C, Saintot M, Scali J, Simony-Lafontaine J, Grenier J, Pujol H.Tumor progression and oxidant-antioxidant status. Cancer Lett 114 (1997) 211-4.

[23] Faber M, Coudray C, Hida H, Mousseau M, Favier A.Lipid peroxidation products, and vitamin and trace element status in patients with cancer before and after chemotherapy, including adriamycin. A preliminary study.Biol Trace Elem Res 47 (1995) 117-23.

[24] Ray G, Batra S, Shukla NK, Deo S, Raina V, Ashok S, Husain SA.Lipid peroxidation free radical production and oxidant status in breast cancer. Breast Cancer Res Treat 59 (2000) 163-70.

[25] Gerber M, Richardson S, Crastes de Paulet P, Pujol H, Crastes de Paulet A.Relationship between vitamin $\mathrm{E}$ and polyunsaturated fatty acids in breast cancer. Nutritional and metabolic aspects.Cancer 64 (1989) 2347-53.

[26] Ames BN. Dietary Carcinogenesis: oxygen radicals and degenerative disease. Science 221 (1983) 1256-64.

[27] Marnett LJ.Lipid peroxidation-DNA damage by melondialdehyde. Mutat Res 424 (1999) 83-95.

[28] Kubatka P, Kalická K, Chamilová M, Ahlersová E, Ahlers I, Bojková B, Adámeková E. Nimesulide and melatonin in mammary carcinogenesis prevention in female Sprague-Dawley rats. Neoplasma 49 (2002) 255-9.

[29] Zieba M, Nowak D, Suwalski M, Piasecka G, Grzelewska-Rzymowska I, Tymińska K, et al. Enhanced lipid peroxidation in cancer tissue homogenates in non-small cell lung cancer.Monaldi Arch Chest Dis 56 (2001) 110-4.

[30] Navarro J, Obrador E, Carretero J, Petschen I, Aviñó J, Perez P, Estrela JM.Changes in glutathione status and the antioxidant system in blood and in cancer cells associate with tumour growth in vivo.Free Radic Biol Med 26 (1999) 410-8.

[31] Doroshow JH, Akman S, Chu FF, Esworthy S.Role of the glutathioneglutathione peroxidase cycle in the cytotoxicity of the anticancer quinones.Pharmacol Ther 47 (1990) 359-70.

[32] Kumaraguruparan R, Subapriya R, Viswanathan P, Nagini S.Tissue lipid peroxidation and antioxidant status in patients with adenocarcinoma of the breast.Clin Chim Acta 325 (2002) 165-70.

[33] Robinson MF, Godfrey PJ, Thomson CD, Rea HM, van Rij AM.Blood selenium and glutathione peroxidase activity in normal subjects and in surgical patients with and without cancer in New Zealand.Am J Clin Nutr 32 (1979) 1477-85.

[34] Wang HP, Qian SY, Schafer FQ, Domann FE, Oberley LW, Buettner GR.Phospholipid hydroperoxide glutathione peroxidase protects against singlet oxygen-induced cell damage of photodynamic therapy.Free Radic Biol Med 30 (2001) 825-35.

[35] Skrzydlewska E, Stankiewicz A, Sulkowska M, Sulkowski S, Kasacka I.Antioxidant status and lipid peroxidation in colorectal cancer.J Toxicol Environ Health 64 (2001) 213-22. 
[36] Halliwell B.The antioxidant paradox.Lancet 355 (2000) 1179-80.

[37] Lu YP, Lou YR, Yen P, Newmark HL, Mirochnitchenko OI, Inouye M, Huang MT.Enhanced skin carcinogenesis in transgenic mice with high expression of glutathione peroxidase or both glutathione peroxidase and superoxide dismutase. Cancer Res 57 (1997) 1468-74.

[38] Kaplan JH, Groves JN.Liver and blood cell catalase activity of tumor-bearing mice.Cancer Res 32 (1972) 1190-4.

[39] Jaruga P, Zastawny TH, Skokowski J, Dizdaroglu M, Olinski R.Oxidative DNA base damage and antioxidant enzyme activities in human lung cancer.FEBS Lett 341 (1994) 59-64.

[40] Britton RS, Ramm GA, Olynyk J, Singh R, O'Neill R, Bacon BR.Pathophysiology of iron toxicity.Adv Exp Med Biol 356 (1994) 239-53.

[41] Yaffee M, Walter P, Richter C, Müller M.Direct observation of iron-induced conformational changes of mitochondrial DNA by high-resolution fieldemission in-lens scanning electron microscopy.Proc Natl Acad Sci USA 5341 (1996) 5341-6.

[42] Reizenstein P.Iron, free radicals and cancer.Med Oncol Tumor Pharmacother 8 (1991) 229-33.

[43] Giler S, Moroz C.The significance of ferritin in malignant diseases.Biomedicine 28 (1978) 203-6.

[44] Marcus DM, Zinberg N.Measurement of serum ferritin by radioimmunoassay: results in normal individuals and patients with breast cancer.J Nat Cancer Inst 55 (1975) 791-5.

[45] Wyllie S, Liehr JG.Release of iron from ferritin storage by redox cycling of stilbene and steroid estrogen metabolites: a mechanism of induction of free radical damage by estrogen. Arch Biochem Biophys 346 (1997) 180-6. 